\title{
Categories of personality, modality and their text-forming function
}

\author{
Elena Bolotova ${ }^{1, *}$ \\ ${ }^{1}$ Don State Technical University, 1, Gagarin square, 344003, Rostov-on-Don, Russia
}

\begin{abstract}
This article covers the issues of studying and scientific linguistic explanation of the categories of personality, modality and their text-forming function. An important reason for referring to the fiction texts was interest in expanding the studied literary material in order to research text linguistics. The studies were carried out using fragments of texts by the following modern prose writers as (based on sentences-examples) Konchalovsky A., Marinina A.B., Ulitskaya L.E., Tokareva V.S. and Gladkiy V.D. The narrative text of the authors' works of fiction is analyzed as a united literary work, expressively combined with the variety of subject-speech planes, with the established various and complex functional relationships. The article represents personality and modality as an integrative text category that determines its cognitive content. Creation of different authors' texts typology on a dominant basis of personality and modality is shown as a linguo-aesthetic text category of modality and personality, which characterizes a literary work when interacting.
\end{abstract}

\section{Introduction}

Currently, many scientists undertake theoretical explorations on a deep, comprehensive linguistic analysis of literary texts and its linguistic features. The interest of specialists in the study of literary texts is always conditioned by the need and desire to explain language as a communication means of human activity, associated with its various aspects, realized through texts.

Since the article is devoted to the problems of modality and personality as textual categories, in the introduction the author tries to reveal the theoretical significance, relevance of the topic, scientific novelty and research methods, to describe the analyzed text material, to define the main goals, objectives, subject and object of the research, to formulate the main provisions of this article.

The relevance of the issues considered in this article is determined by the expediency of developing a modern discursive method for the study and discussion of the categories of personality and modality as universal, providing a continuous linguistic process of cognition in the study of the text-forming function of modality and personality categories based on the material of works of authorship in various aspects: pragmatic, functionalcommunicative, linguistic-personal, etc. Today, prose texts of the memoir, detective and adventure genre are only becoming a subject for the study of linguists, since they have a

\footnotetext{
* Corresponding author: bolotovaelena2008@rambler.ru
} 
number of characteristic features (fundamental issues of perception, reflection in texts of the virtual world, detectiveness, memoiristics, etc.), which are not yet sufficiently covered in research works of specialists.

Modern linguistics, the theory of language in particular, reasonably focuses its attention on certain key aspects of objects - linguo-personalological, communicative, functional, pragmatic, arranging and specifying their special systemic relations.

Considering modern trends, the textual category of personality and the textual category of modality arouse great research interest among modern linguists, because they are the designation of "a person in a language" [1].

The purpose of the study makes it possible to identify the text-linguistic specificity of the field of literature, as well as to establish the national specificity of prose texts and idiostyles of the authors, to describe the linguistic means that form the category of personality and modality in the modern text. The text is addressed to a linguistic person and is a product born of a linguistic person.

Therefore, the purpose of the work was to analyze and study the implementation of textual categories, consider the textual categories of personality and modality, as well as understand and study the analyzed texts.

The object of research in this article is the text-forming categories of personality and modality in modern linguistics.

The subject of the research is the lexical and grammatical means of expression, as well as the text-forming function of the category of personality and modality in the texts of prose writers popular in Russia in the second half of the XX and early XXI centuries [1,2].

During the research, the author solves a range of certain linguistic tasks that determine their achievement, therefore, the study of textual categories is currently extremely relevant, because it is impossible to talk about anything (the object of research) without naming or explaining the category of this object.

The theoretical value of the research work is predetermined by the introduction of some new facts for solving the accumulated dilemmas in text theory, grammar, and cognitive linguistics [3]. This is related to the consideration of the cognitive essence of the categories of modality and personality with the aim of explaining their conceptual phenomenality, identifying and describing the conceptual framework of the national language, based on the materials of the texts of fictional prose analyzed in the article [4].

The following authors became the framework for the theoretical basis of this work: Arutyunova N.D., Akhmanova O.S., Bakhtin M.M., Benveniste E., Bondarko A.V., Galperin I.R., Kolshansky G.V., Kostomarov V.G., Kubryakova E.S., Malycheva N.V., Nemets G.P., Turaeva Z.Ya. and many other scientists [1, 2, 4, 5].

Note that only since the 60 s of the XX century, in the works of linguists, such a direction as the grammar (linguistics) of the text arose and became firmly established. In linguistics, the term grammar is used in a multi-valued interpretation with the inclusion of oral speech. The text in the process of study is perceived within the framework of psycholinguistic and text linguistics. Note that a fictional prose text consists of a group of sentences that are integrated into a whole by a core theme and main idea, in general terms, connected with the complete sequence of signs.

However, it would be a mistake not to see that the main features of each analyzed text are the unity of its individual parts (thematic, compositional), and the presence of grammatical connections between its parts (sequential or parallel), the relative completeness of the text and semantic integrity.

The theme of a piece of work is often reflected in its title (heading) and is what is communicated in the text. In addition to the theme, the text may contain digression. The author's attitude to the phrases of speech, its assessment of the described action (in lyrical 
digressions, when using various means of language, in revealing the topic of the text) usually conveys the main idea of the text of a literary work.

Expressing the most important idea, each author quite often goes "up the steps", moves from one part of the work to another, but the text is not an end in itself, it is the material with which the author works.

The scientific novelty of this work is determined by a complex of various tasks and issues that make up the area of the problem of the linguistic categories of personality and modality studying. The area of the problem is that modality and personality (linguoaesthetic textual categories) characterizing a literary work are first explored in their contact within the author's texts (memoirs, novels, stories) of modern prose.

\section{Description of research methods for the category of personality and modality}

The methodological basis of the article, its sources and theoretical basis are those scientific works that are associated with the identification, research, analysis and description of linguistic means that form the categories of modality and personality in the modern text. In this regard, it is important to identify the national specificity of different texts of modern prose texts and the specificity of the authors' individual style. The study of linguistic means and ways of their impact on the reader is a topical issue for modern linguistics.

In the work on the article, research methods contributing to the maximum reliability of the results and conclusions were used: the method of functional-grammatical and analytical description of language categories, the method of observation, comparison and typology of the analyzed sentences when considering individual fragments of the author's texts.

\section{Subject matter of the work}

The Russian language ranks the fourth most widely spoken language in the world. Nobody announces that Shakespeare spoke English, but the whole world knows and says that the Russian language is the language of the great Pushkin.

Fiction, created in Russian, is of great universal human significance for the entire world culture.

The Russian language, in spite of everything in the world, is very popular both in the scientific community and among the intellectual elite. This respect is based on the great Russian literature of the past.

There is an opinion on the intellectual market that at present Russia is an empire of great culture, including the Russian language, which has retained its identity and uniqueness over a long historical period. It absorbed the richness of the Eastern and Western countries languages, as well as the heritage of the Greek, Byzantine, Latin, Old Slavonic, Romance and Germanic nations.

Note that the Russian language has become a source of activities development of the Russian people (science, culture, politics, literature). In the process of formation, the Russian language organized, stylistically differentiated and historically balanced into a highly developed and rich language [6]. Therefore, today the Russian language has unique and extremely valuable qualities: maximum flexibility, not limited to emotionality in the structure of sentences, information content, etc.

For a long time, linguists have not lost interest in a detailed study of the text, the desire to deeply study textual connections with the diverse aspects of human communicative activity, realized through the text. At the center of many studies is the area for the study of the subjective-human factor [7]. The contemporary theory of language is looking for the 
integrity of various aspects of genre verification and categorical patterns of the Russian language.

The category of personality, ideologically speaking, is in the qualitative status of "supercategory" and the author of any prose text conducts an exposition based on his practical point of view, which is associated with extralinguistic reality.

It should be pointed that the decisive factors determining the selection of diverse linguistic means taking part in the construction of various texts are situational, genre (objective) and subjective (author's personality), since the text objectively reflects the worldview, world outlook, attitude of the author, etc. [8].

The content of the article is based on the conceptual theory of anthropocentrism and subjectivity, which makes it possible to consider language in the form of a semiotic system, and helps to describe the fundamental referential features of words related to the subjects of speech. In modern linguistics, there has been a major methodological shift - the transition from immanent linguistics to anthropological.

Anthropocentrism is the figure of a person in language, i.e. the study of the subjectivehuman factor in the language system (egocentricity, deictic categories, linguistic analysis, etc.). The study of certain linguistic lexical categories has not yet acquired the volume that it deserves in the light of anthropocentric perspective $[9,10]$. In linguistics, anthropocentrism believes that a man is the paradigm, the center and the highest goal of the universe.

A compelling argument to turn to literary texts was the need to expand the list of research materials (texts) to study their linguistics. All the works were chosen by a reason and according to the following criteria: by prosaic character, typical frequency, by the probabilistic characteristic of connections of at least two categories, for example: personality, modality; simplicity, economy, efficiency (redundancy and sufficiency) of means of expression.

It is general practice, within the framework of the philological analysis of a literary work, scholars limit themselves only to examining fragments of the text. However, they are not always signs of the reader's perception of the work.

Linguists have been studying texts for quite a long time, limiting themselves to the framework of analyzing the relationships of individual elements of the language system inside the texts, that is, the first pole in the text. The research was carried out with the aim of identifying and modeling relationships within the text horizontally in the descriptive text, within a specific system and structural paradigm.

Superphrasal unity, micro themes, semantic units, paragraphs, a complex syntactic whole were distinguished in the text as dissimilar units with semantic syntactic cohesion of text components, etc.

Recently, the text has become a "testing area" for linguists in terms of research and testing of many linguistic concepts (text as a functional, conceptual system, etc.). The list of text categories continues to grow.

Examples of sentences in the text of the article (empirical base) are presented from the prose works of the Russian intellectuals, written in Russian. The choice is motivated by the thematic correlation of the works and the relatively high literary skills of the authors.

Examples of sentences in the text of the article are provided from the works:

Konchalovsky A.S. - "Unpleasant truths" и "Elevating falsehood";

Marinina A.B. - "Memory Phantom";

Tokareva V.S. - collections "Male Fidelity" and "Between Heaven and Earth";

Ulitskaya L.E. - "The Kukotsky Enigma" and "Sincerely Yours, Shurik";

Gladkiy V.D. - "Insidious luck".

Recently, the above writers have been ranked among the best prose writers in modern Russia, actively read and discussed by readers. 
Text is considered to be the main unit of communication, since communication between people is carried out not in words or individual expressions, but in integral texts. In the process of communication, the text is considered a special unit, because it is a verbal piece of work, which can be oral and written.

The text is a verbal unity (written, oral) with a complete content (meaning) and speech action, expressing and forming the content of the work, which combines diverse speech, subjective plans in dynamic relations.

It is reasonable to understand the differences between the concepts of text and textforming categories. The text category manifests itself at the textual level, and the textforming category contributes to the construction of various texts. The text category is not realized as a text-forming function on a permanent basis, but the text-forming linguistic category is constantly involved in the implementation of the textual and text-forming functions.

The development of linguistic research in recent decades has been marked by an increased desire to explore the possibilities of language. Scientists have resorted to taking into account the actual linguistic functioning in all manifestations.

Apparently, the non-specific approach to the study of the text leads to the language schematization in the theory of the text and a reduced attention to its important properties. The famous specialist Rozhdestvensky Yu.V. expressed his opinion that "the philologist writes for eternity and his works begin to be studied after his earthly life" [11]. Consequently, the main task of modern linguistic science of text is the typological description of literary texts. Modern professional speech actions cannot exist without knowledge and rules of forms of communication and verbal impact [12]. A person should be able to critically and responsibly understand what he writes and says himself or is written and spoken about him, that is, to have his own opinion.

Linguistic categories of personality, modality, locality, temporality, assessments are logically connected with the text-forming function. The above listed text categories are specific means with which the author of the text can change a particular speaker's "I". The author can also change the order of alternation of subjects in case any events change.

The text-forming category of personality in the process of research is analyzed by linguists as a linguistic category or the concept of an "author's image". It does not matter in what language the text of a literary work is written, the importance is that the "author's image" is a special organizing force of the written literary text. This force unites all parts of the text created by the author, which adheres to a single worldview and is abstracted from the idealization and biographical accuracy of the narration of the described events.

It may be said that the linguistic category of personality is common to texts written in other languages, and not only in Russian. Numerous linguistic studies of specialists show that the text-forming categories of modality and personality are of significant interest for linguistics scholars. The lexical, semantic and grammatical means by which the author organizes and constructs the text that obeys his intention reinforce this interest from a practical point of view.

As a connecting link between the specific subjective and the objective, the author of a certain text, as well as the character become the fundamental categories of the literary text and rightfully occupy a dominant position in the literary text, due to their absolute anthropocentricity.

Categories of text (textual) are divided into text-forming (personality, modality, temporality, coherence, locality) and non-text-forming (quality, quantity, reason, effect, politeness).

Personality, expressed in various lexico-semantic, grammatical means, most often in the texts uses vivid appeals to readers, emotional and expressive vocabulary, rhetorical questions, introductory constructions and certain linguistic expressions, epithets, 
authorization verbs, modal verbs, parceled constructions, connotative meanings words, impersonal sentences, associative-figurative comparisons, creative conjunctions, anthropomorphisms, etc. [13].

Linguists classify the category of personality as deictic linguistic categories that are based on the grammatical category of person. Zolotova G.A. claims that language is egocentric and anthropocentric. Proceeding from this "I-speaker" is in the central place of our language [5].The speech plans of the author and of the character in the texts are separated from each other and are mutually impenetrable.

Note that there are almost no other categories, about the linguistic essence and composition of which so many ambiguous points of view would be stated, and therefore in linguistics there is still no unequivocally accurate opinion about the nature and content of the text-forming categories of personality and modality. Since the linguistic category of personality is closely related to the concepts of genre, style of speech, it is clearly characterized as text-forming.

The text-forming category of personality actively interacts with other linguistic categories of the text. Personality is the starting point of many linguistic categories like modality, temporality, locality and takes the place of the leading category that determines the syncretic-meaningful author's text of a particular work. Linguists consider imagery, evaluativeness and information content to be the main characterizing means to express the text-forming category of modality and personality.

In the literature on linguistics, the category of modality is usually considered as twoaspect, since various sentences (statements included in the context) can not only reflect extra-linguistic reality, which exists objectively, but contains a subjective assessment of the event displayed in the text.

When marking open relations between the interpretation of certain information by the speaker and the actual reality of the speaker, the conceptual category of modality can enter into the text-forming category of personality [14].

In a literary utterance (discourse), many characters are active participants in the events portrayed by the author. Therefore, they can independently demonstrate their personal attitude to everything that happens [15]. When the author is outside the described events in the text, he still has more information about them than heroes created by him. The author tries to describe the world clearly and eloquently from all significant positions.

It is necessary to point out that within the framework of one author's text, replacements and alternations of speech, vivid subjective author's plans, as well as characters with a profound display of the perspective of the narration of the work content, take place. This allows to emphasize the versatility and counterpoint of the literary description.

The grammatical analysis of sentences is based on texts posessing the properties that determine the specific characteristics of the analyzed sentence and its functioning features.

It is advisable to emphasize that in the process of analyzing the content of a literary text, the need to highlight the individual components of such a triad as "the meaning of the text the meaning of the work - the meaning of the text" is revealed.

Currently, in research works on linguistics, questions on the linguistic and speech status of the text, its position in the dyad "language - culture", as well as in the discursive experience of society are considered large-scale [16]. The text attracts special attention of linguists, being a unit of the text level.

In the below examples, we are explaining the use of the categories of personality and modality, their text-forming function and analyzing the author's texts, for example:

(1) My fate keeps me tight-lipped and does not give me big favours. And anyway I was not born for earthshaking meetings. [17].

(2) Looks like I got caught in a whirl of some intrigue. And it sucks me in more and more, dragging me to the very bottom. [18]. 
(3) I didn't ask permission from any visiting committee. And anyway I didn't ask anyone, didn't inform, didn't register at the Soviet consulate. [19].

Note that when beginning the sentence with the conjunction "and" the reader is waiting for the continuation of the story. For example:

(4) It's good if the waves carry you to the soft sandy shore. But it happens differently. And then just hang in there. [18].

(5) He loved me so much that he agreed to work for free. And we wrote two scripts without a contract, without any confidence that they will be directed. [20].

(6) You are a friend of Valeria, she told me about you, said the old man, sucking on loosely set teeth. And then Shurik guessed that this old man was a Catholic priest, to whom Valeria once went to Lithuania, to the deep forest regions, where he settled after ten years in the camps. [17].

The sentences express various feelings, the order of phenomena (thoughts) and the connection between them. It would be a mistake failing to notice that coordinating conjunctions can express a relationship called the connection of syntactic equality and equivalence between homogeneous members of a sentence that perform the same syntactic function, as well as between different parts of a compound sentence, for example:

(7) Absorbed with gloomy thoughts, I let my hair down for a while. And the vengeance for this was swift. [18].

(8) The shooting did not last long, two minutes at most. And then everything suddenly went silent. [18].

It would be reasonable to note that conjunction "but" focuses on opposites, contradictions, virtual and fantastic, on the convergence of the incompatible [21]. Therefore, such sentences with the conjunction "but" always serve as oppositions, because they have the meaning of comparison, for example:

(9) She admires talent, if any, just as much as this talent makes books sellable, and not because she likes these books. But I don't care, it doesn't offend me and doesn't hurt me. [22].

(10) A cloud is pouring down on the businessman's face: why to establish acquaintance with the lower class. But for Suzann there is no upper and lower class: all people are humans for her. [23].

(11) And the door was ready to open, even as if a shadow ran along the crack of the opening in the rock - I was invited to enter there. But I was scared, and then sensing my fear the door turned into a relief on a white rock again, and it deftly became more and more flat under my gaze, and everything was overgrown with the white flesh of the stone, until it completely disappeared. [24].

Note that the category of the author's modality forming the anthropocentricity of a literary text helps to determin the nature of the relationship between modal plans, and the author's modality contributes to the implementation of the author's communicative intention in the category of text modality.

From a number of the above examples, it becomes clear that the authors quite frankly reflect and talk about the dramatic events that actually happened in their personal and creative life.

Consequently, it is possible to interest the reader in the way of a correctly described character due to the use of various modal means (modal-textual meanings) presented by the speech subject. Thus, a literature-fiction text with modality is usually determined by the explicit relationships of the link "speaker - connection - existing reality".

The categories of modality and personality are global in terms of contact with the language: they penetrate into all its systems and affect all linguistic texts (works). The category of modality connects external phenomena with the inner world of a person. The category of modality is objective (space, time, face), as well as subjective, showing the 
relationship to the expressions of the speakers, which allows you to organize and build a full-fledged literary text using the textual category of personality.

The modality of any pictorial prosaic text realizes the relationship between the author and the original, descriptively and evaluatively. The original is portrayed in the text in all sorts of episodes in which the author is present. The author's attitude is revealed in the objective, subjective and modal terms, while showing the likelihood of the described event and its reliability in the semantic and emotional terms, both with negative and positive assessments of the stated fact. For example:

(12) The beast that sat in front of him looked at him with hard blue eyes, had steel jaws, a mirtal grip and a diamond-hard ambition corresponding to his juvenile nickname. But they also had a lot in common: great teachers, defective bloodline - if a Jewish timber merchant can be compared to a Siberian breeder - camp experience and first-class brains. [24].

To understand the images, the authors use all linguistic means, since the artistic style supposes preselection of linguistic means [25].

In the language of fiction works, in particular, in prose, the potential reserves of linguistic means are revealed in various ways.

It should be said that modality is one of the most mysterious categories of language and the system of thinking, while the linguistic category of personality can be revealed in every author's utterance. Usually, any speech communication, from interjection words to full text, is accompanied by the category of modality.

The concept of "text modality" in linguistics is relatively new and has not yet been sufficiently developed by scholars. Thus, it is difficult to overestimate the significance of the text modality as a category.

The categories of modality and personality are often found in the process of using special markers as modal words, and in certain types of speech communication and the image of the narrator created by the author of the text.

In this work, we study personality at the level of presenting statements in sentences that are included in the context, because the main material of the article consists of coherent literary texts that have appropriate concepts and attitudes from the practical point of view of the author, as well as the characters involved. Concepts and attitudes are realized in the author's speech (direct, improperly direct speech and internal monologue).

There is no reason to doubt that the linguistic category of personality is considered extremely common to all languages in the world and therefore it is considered universal.

The category of linguistic modality conducts and directs any communicative utterance, starting with an interjection speech act and ending this utterance with a full-fledged text. For example:

(13) I accepted the offer with gratitude. And in fact, I no longer had the strength to go somewhere far away, but I liked the woman... [22].

(14) Naturally, I agreed. And then he peppered Musya with questions hoping that her detailed answers would finally awaken my memories that fell into a coma. And again my hopes were not justified, I didn't remember anything. [22].

The main parameters of the author's linguistic picture of the world should be recognized as a diverse subject world, artistic time and space, a built system of the main actors in it and invariant motives, as well as artistic ontology.

In the process of analyzing the text, 11 works were considered by 5 modern prose writers of different literary genres (memoirs, detective stories, novels, short stories), with a total volume of 2,920 pages.

The comparative analysis of the texts of different writers undertaken by us testifies to a similar use of the categories of modality and personality in them, however, in a different 
quantitative ratio. So, when analyzing the texts of works by different authors, we found differences in the sentences they used and obtained the following results:

- on each of the 736 pages of A. Konchalovsky's memoir text, there are on average 6-7 simple and complex sentences using the categories of modality and personality;

- on each of 576 pages V.S. Tokareva revealed on average 5-6 such proposals;

- on the pages of L.E. Ulitskaya (on each of the 891st) there are 4-5 complicated, very long and hard-to-read sentences;

- on each of the 416 pages of the text of the work of A.B. Marinina, there are 3-5 similar simple and complex sentences;

- on each of the 301 pages of the work of V.D. Gladkiy identified 2-3 simple sentences.

The use of the categories of modality and personality by the authors of works, in our opinion, helps to draw conclusions about their linguistic and imaginative world, reflected in the language of the texts of memoirs, detective stories, novels and stories.

Thus, the analysis and statistical calculation confirms the lesser use of sentences with the use of the categories of modality and personality in the texts of detective works of A.B. Marinina and V.D. Gladkiy.

Table 1. The result of the analysis of proposals.

\begin{tabular}{|c|c|c|c|c|}
\hline $\begin{array}{c}\text { No } \\
\mathbf{p} / \mathbf{p}\end{array}$ & Author, title of the work & $\begin{array}{c}\text { Total pages } \\
\text { analyzed }\end{array}$ & $\begin{array}{c}\text { Number of } \\
\text { sentences on } \\
\text { the 1st page }\end{array}$ & $\begin{array}{c}\text { Result from the } \\
\text { total flow of } \\
\text { sentences in the } \\
\text { text (\%) }\end{array}$ \\
\hline 1. & $\begin{array}{c}\text { A.S. Konchalovsky "Low } \\
\text { Truths", "Exalting Deception" }\end{array}$ & 736 & $6-7$ & $\mathbf{5 5 - 7 0}$ \\
\hline 2. & $\begin{array}{c}\text { A.B. Marina "Phantom of } \\
\text { Memory" }\end{array}$ & 416 & $3-5$ & $\mathbf{3 5}$ \\
\hline 3. & $\begin{array}{c}\text { V.S. Tokareva Sat. "Male } \\
\text { Fidelity", "Between Heaven } \\
\text { and Earth" }\end{array}$ & 576 & $5-6$ & $\mathbf{4 0 - 4 5}$ \\
\hline 4. & $\begin{array}{c}\text { L.E. Ulitskaya "Casus } \\
\text { Kukotsky", "Sincerely yours } \\
\text { Shurik" }\end{array}$ & 891 & $4-5$ & $\mathbf{4 0}$ \\
\hline 5. & V.D. Gladkiy "Insidious luck" & 301 & $2-3$ & $\mathbf{2 5 - 3 0}$ \\
\hline
\end{tabular}

\section{Conclusion}

In conclusion, it is reasonable to emphasize that the presented fragments (examples of sentences) from the author's texts were selected according to certain individual speech means that determine the artistic and aesthetic worldview attitudes of an individual writer.

The analysis carried out in the study showed the content of the texts under consideration, as well as the contextual conditions for the use of the linguistic category of modality and personality, which testifies to the text-forming function of these linguistic categories in the texts.

Authors of fiction thoughtfully select individual communicative means for writing their texts, which, in their opinion, should meet all the necessary aesthetic requirements of the writer and reader.

The author uses such linguistic means (composition, system of word-pictures), which can motivate the peculiarities of the author's specific vision of the linguistic picture of the world, as well as thinking and his ideological attitudes.

An important role in understanding the text-forming essence of personality and modality is played by lexical and grammatical categories, therefore, when studying them within the structure of the studied text categories, we can say these categories lead the list 
of all text categories, since obeying the author's intention, they predetermine the text structure and organization.

At present there is a certain number of linguistic works performed with an anthropocentric focus, but the lack of knowledge of the linguistic theory of personality and modality is still quite noticeable.

We hope that the analysis of the texts of modern prose writers makes it possible to open new areas in linguistics that require special research.

Of course, as evidenced in practice, the problem involved raised is not exhaust by a description only. There are no such texts in the literature that would not record any events of people's life with their linguistic comprehension.

The language of any person in the process of forming verbal activity usually acts as a creative and aesthetic function, laid over the most important linguistic functions, such as communicative and cognitive.

Thus, language can be ranked among creativity and considered in the creatological aspect: a new worldview, a new scientific direction, a new paradigm, while having the opportunity to explore the issues of sensualistic interaction of a certain creative individual (author or person) with all kinds of forms of universal human consciousness.

Therefore, we found out that the textual category of personality and the textual category of modality are conceptual categories that have penetrated the canvas of the author's text, in which there are no generalized words. In this kind of texts, everything is usually interconnected: relationships, the author's viewpoint, and much more. This fixes and consolidates the author's work, explains the role, location and functional process of any work of art.

\section{References}

1. E. Bolotova, Journal of Language and Communication, 6, 98-100 (2011)

2. E. Bolotova, G. Gavrilova, N. Grigorieva, et al., Sentence and text: consistency and functionality (AkademLit, Rostov-on-Don, 2015)

3. J. Nuyts, Cognitive linguistics and functional linguistics. Handbook of cognitive linguistics (Oxford University Press, Oxford, 2007)

4. N. Malycheva, Journal of Philological Sciences, 4, 48-55 (2009)

5. G. Zolotova, Essay on the functional syntax of the modern Russian language. On the modality of a sentence in the Russian language (Science, 1973)

6. M. Sadovnikova, N. Kumpan, Norwegian Journal of International Science Development, 2(3), 96-100 (2017)

7. T. Martsinkovskaya, E. Balashova, N. Poleva, Journal European Proceedings of Social and Behavioural Sciences, Future Academy (online), 94, 459-466 (2020)

8. M. Besemeres, Journal of Multilingual and Multicultural Development, 25(2, 3), 140158 (2004)

9. D. Ivanov, D. Lakerbai, Philological Sciences. Scientific Reports of Higher Education - Philological Sciences. Scientific Essays on Higher Education, 3, 3-12 (2019), DOI: 10.20339/PhS.3-19.003

10. K. Janicki, International Journal of Applied Linguistics, 20(1), $73-94$ (2010)

11. Y. Rozhdestvensky, Lectures on general linguistics (Moscow, 1990)

12. C. Berger, Journal of Language and Social Psychology, 26, 215-233 (2007)

13. S. Bylkova, I. Kovtunenko, V. Borisenko, et al., XLinguae, 11(2), 95-105 (2018), ISSN 1337-8384, eISSN 2453-711X. 
14. I. Kovtunenko, Journal Russian Language Studies 16(1), 63-90 (2018), URL: http://journals.rudn.ru/russian-language-studies/article/view/18014 DOI: https://doi.org/10.22363/2313-2264-2018-16-1-63-90

15. V. Dementyev, Russian Journal of Linguistics, 4, 103-121 (2016), DOI: 10.22363/2312-9182-2016-20-4-103-121

16. N. Boeva-Omelechko, M. Zheltukhina, O. Ryabko, et al., Space and Culture, 6(4), 112121 (2018), DOI: 10.20896 / saci.v6i4.387.

17. L. Ulitskaya, Yours sincerely Shurik (Eksmo, Moscow, 480 (2018)

18. V. Gladkiy, Insidious luck (Tsentrpoligraf, Moscow, 2008)

19. A. Konchalovsky, Low truths (Collection Top secret, Moscow, 1998)

20. A. Konchalovsky, Exalting deception (Collection Top secret, Moscow, 1999)

21. A. Rudenko, G. Mogilevskaya, Man in India, 97(23), 533-541 (2017)

22. A. Marinina, Phantom of memory (Eksmo, Moscow, 2017)

23. V. Tokareva, Collection of Male Fidelity (AST, Moscow, 2016)

24. L. Ulitskaya, The Kukotsky case (Eksmo, Moscow, 2016)

25. L. Alba-Juez, J.L. Mackenzie, Emotion processes in discourse (John Benjamins Publishing Company, Amsterdam, 2019), DOI: 10.1075/pbns.302.01alb 